\title{
Some molecular descriptors for non-specific chromosomal genotoxicity based on hydrophobic interactions
}

\author{
Susanne B. Dorn · Gisela H. Degen · Hermann M. Bolt • Jaap van der Louw • \\ Frederique A. A. van Acker · Diels J. van den Dobbelsteen · Jos P. M. Lommerse
}

Published online: 14 March 2008

(C) Springer-Verlag 2008

\section{Erratum to: Arch Toxicol}

DOI 10.1007/s00204-007-0256-8

In this article, the name of one of the authors has been misprinted. The correct name is:

Diels J. van den Dobbelsteen

The authors apologize for any inconvenience this might have caused.

The online version of the original article can be found under doi: 10.1007/s00204-007-0256-8.

S. B. Dorn · G. H. Degen · H. M. Bolt

Institut für Arbeitsphysiologie an der Universität Dortmund

(IfADo), Ardeystr. 67, 44139 Dortmund, Germany

J. van der Louw

Department of Medicinal Chemistry,

Organon, Oss, The Netherlands

F. A. A. van Acker - D. J. van den Dobbelsteen

Department of Toxicology and Drug Disposition,

Organon, Schaijk, The Netherlands

J. P. M. Lommerse

Department of Molecular Design and Informatics,

Organon, Oss, The Netherlands

H. M. Bolt ( $\square)$

IfADo, Ardeystr. 67, 44579 Dortmund, Germany

e-mail: bolt@ifado.de 